\title{
Kinetics of the Aromatic Nucleophilic Substitution Reaction Between 1-Fluoro-2,4-Dinitrobenzene and Perhydroazepine in Ethyl Acetate + Chloroform Solvent Mixtures
}

\author{
P. M. Mancini, G. Fortunato and A. J. Terenzani \\ Departamento de Química, Área de Química Orgánica, Facultad de Ingeniería Química, Universidad \\ Nacional del Litoral (U.N.L.), Santiago del Estero 2829, 3000. Santa Fe, Argentina \\ E-mail: pmancini@fiqus.unl.edu.ar
}

\begin{abstract}
In the present work, the kinetic behavior of the title reaction in ethyl acetate + chloroform solvent mixtures is studied. The experimental results are compared with previous findings.
\end{abstract}

\section{Introduction}

In a recent publication [1a], the kinetic synergetic effect of the ethyl acetate + chloroform solvent mixtures on the reaction between 1-fluoro-2,4-dinitrobenzene and piperidine (Pip) or morpholine (Mo) was reported.

We observed a special enhancement effect on the reaction rate at some intermediate compositions of the mixed solvents, with respect to the corresponding one in the pure components, part of the mixtures. This phenomenon was explained as a combination of factors related to the variation of the influence of base catalysis and specific solvent effects, particularly hydrogen bond interactions.

\section{Experimental}

The kinetics of the reaction was studied by monitoring the absorbance of the product at $\mathrm{ca} 383 \mathrm{~nm}$ with a Perkin-Elmer Model $124 \mathrm{UV}-\mathrm{V}$ is spectrophotometer equipped with a data-acquisition system based on a microprocessor.

The reactions were carried out under pseudo-first order conditions. The pseudo-first order $\left(k_{\varphi}\right)$ and second-order $\left(k_{\mathrm{A}}\right)$ rate constants were obtained as described previously [1].

\section{Results and discussion}

The variations of the second-order rate coefficients $k_{\mathrm{A}}$ of the studied reaction, measured at $25^{\circ} \mathrm{C}$ in ethyl acetate + chloroform solvent mixtures, are shown in the figure as a function of the mole fraction 
of the cosolvent, for the maximum and minimum explored concentrations of perhydroazepine.

In spite of fact that the kinetic synergetic effect is observed over the whole range of amine concentration, this special effect is more significant at high values of the nucleophile concentration and in the cosolvent rich zone.

These results are not in agreement with those obtained [1a,2,3] for the corresponding reactions with piperidine or morpholine as nucleophiles in which the kinetic synergetic effect was observed at low amine concentrations and in the cosolvent poor zone.

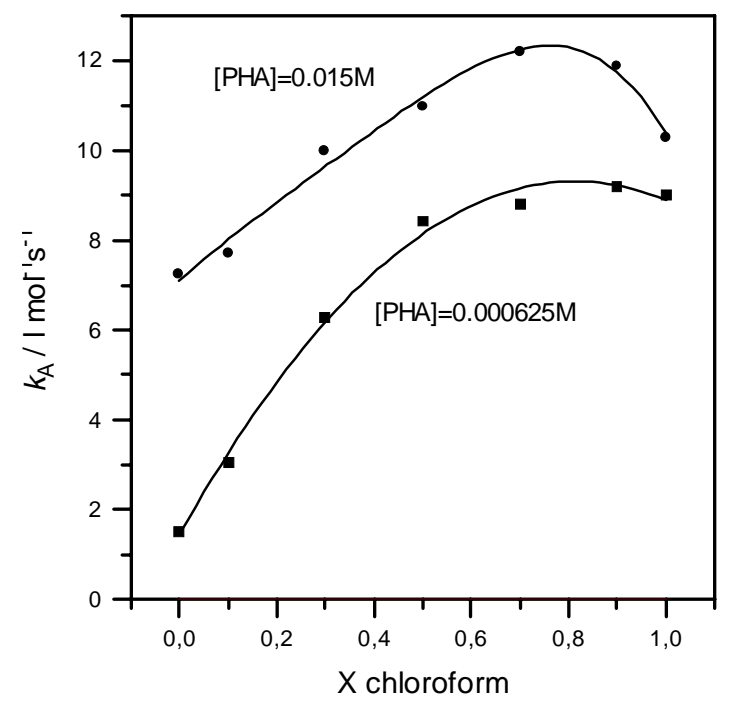

Acknowledgment: The authors are grateful to the C.A.I.+D. Program of the U.N.L. for the financial support. (Projects: 94-0858-007-054 and 96-00-024-162).

\section{References and Notes}

1. (a) Mancini, P.M.; Terenzani, A.; Adam C.; Vottero, L.R. J. Phys. Org. Chem. 1999, 12, 713; (b) Mancini, P.M.; Terenzani, A.; Adam C.; Vottero, L.R. J. Phys. Org. Chem. 1999, 12, 207.

2. Mancini, P.M.; Terenzani, A.; Adam, C.; Vottero, L.R. XXII Congreso Argentino de Química, La Plata, 1998.

3. Mancini, P.M.; Terenzani, A.; Adam, C.; Vottero, L.R. XI Congreso Argentino de Fisicoquímica y I Congreso de Fisicoquímica del Mercosur, Santa Fe, Argentina, 1999. 